\title{
Effectiveness of the EMPOWER-PAR Intervention on Primary Care Providers' Adherence to Clinical Practice Guideline on the Management of Type 2 Diabetes Mellitus: A Pragmatic Cluster Randomised Controlled Trial
}

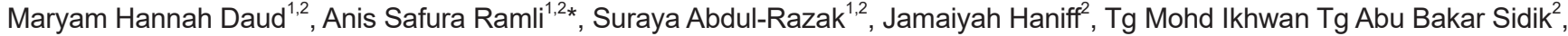 \\ Nur Khairul Bariyyah Mohd Hatta ${ }^{2}$, Sarimah Mahmood ${ }^{1}$, Sharmila Lakshmanan ${ }^{2}$ \\ ${ }^{1}$ Department of Primary Care Medicine, Faculty of Medicine, Universiti Teknologi MARA, Selangor, Malaysia; ${ }^{2}$ Institute of \\ Pathology, Laboratory and Forensic Medicine (I-PPerForM), Universiti Teknologi MARA, Selangor, Malaysia; ${ }^{3}$ Clinical \\ Epidemiology Unit, Clinical Research Centre, Ministry of Health, Kuala Lumpur, Malaysia
}

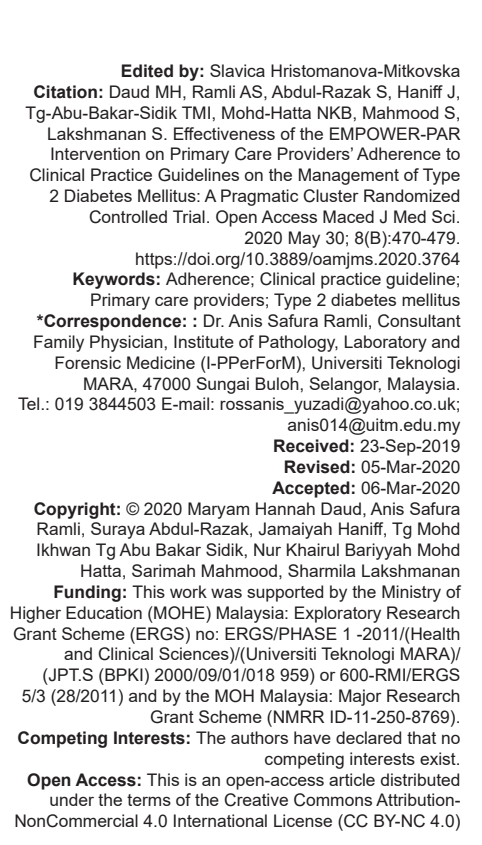

\section{Abstract}

AIM: The objective of this study was to evaluate the effectiveness of the EMPOWER- participatory action research (PAR) intervention, a multifaceted strategy based on the chronic care model (CCM) on primary care providers (PCP) adherence to type 2 diabetes mellitus (T2DM) clinical practice guideline (CPG) in the Malaysian primary care setting. METHODS: This was a pragmatic cluster randomized controlled trial -PAR conducted in ten public primary care clinics in Malaysia. Five clinics were randomly selected to provide the EMPOWER-PAR intervention for 1 year and another five clinics continued with usual care. The outcome measure was the absolute change in the proportion of PCP's adherence to T2DM CPG captured using the "Indicators of Care Pro forma," based on the recommendation by the Malaysian CPG on the Management of T2DM. Data were collected from the patients' medical records, at baseline and at 1-year follow-up; and were analyzed using mixed method model.

RESULTS: A total of 888 patients were recruited at baseline; 471 were in the intervention and 417 were in the control group. There was no significant demographic difference between the two groups at baseline except for ethnicity. At 1-year, $455(96.6 \%)$ and $406(97.3 \%)$ patients in the intervention and control groups completed the study, respectively. There were significant improvements in the absolute change in the proportion of PCPs' adherence to T2DM CPG in the intervention group compared to the control group at 1-year follow-up in several indicators of care. These included the recording of BMI $(0.6 \%$ vs. $-1.8 \%, p<0.001)$; performing foot examination $(2.4 \%$ vs. $0.6 \%$, $\mathrm{p}<0.001)$; performing funduscopy/fundus photography $(1.5 \%$ vs. $0.3 \%, p<0.001)$; monitoring renal profile $(0.9 \%$ vs. $-0.6 \%, p=0.001)$; measuring urine protein $(1.2 \%$ vs. $0.6 \%, p<0.001)$, and giving lifestyle modification and selfmanagement advice $(1.2 \%$ vs. $-0.3 \%, p<0.001)$ in the intervention versus control groups, respectively.

CONCLUSION: The EMPOWER-PAR intervention has been proven to be effective in improving the PCPs' adherence to T2DM CPG in several indicators of care. Findings from this study provided objective evidence of the effectiveness of multifaceted intervention based on the CCM in the Malaysian public primary care setting.

TRIAL REGISTRATION: Registered with: ClinicalTrials.gov: NCT01545401. Date of registration: $1^{\text {st }}$ March 2012.

\section{Introduction}

Type 2 diabetes mellitus (T2DM) has become a universal public health problem as the prevalence dramatically escalated over the past 20 years in numerous parts of the world [1], [2]. The International Diabetes Federation (IDF) estimated that 382 million people had diabetes worldwide in 2013 and predicted that the prevalence will rise to 592 million in 2035 [2]. Asia is greatly affected by the rising prevalence of T2DM, where more than $60 \%$ of the world's T2DM population are Asians [3].

Malaysia, a multi-ethnic nation consisting of Malays, Chinese, and Indians, is also experiencing a
T2DM epidemic. Its prevalence among adults aged $\geq 18$ years old has dramatically increased from $6.3 \%$ in $1986,8.3 \%$ in $1996,11.6 \%$ in $2006,15.2 \%$ in 2011 to an astounding $17.5 \%$ in 2015 [4]. Numerous factors have contributed toward this huge upsurge over the past 4 decades. These include urbanization, industrialization, and motorization due to its fast economic development. Undoubtedly, these factors have contributed toward its population to adopt a more sedentary lifestyle with excessive calorie intake [5], [6]. The World Health Organization has projected that Malaysia would have a total of 2.48 million people with T2DM by the year 2030 compared to 0.94 million in 2000 [7]. Based on the disability-adjusted life years 
estimation, T2DM was the $9^{\text {th }}$ leading cause of disease burden in Malaysia [8].

Clinical practice guidelines (CPG) have been developed to improve the quality of care by emphasizing key clinical recommendations based on current evidence, including for T2DM [9]. Evidently, adherence to CPG prevents complications in patients with T2DM, improves health-care outcomes, and reduces mortality and health expenditure [10]. However, adherence to CPG varies widely among doctors as some clinicians considered CPG being impractical and too rigid to apply to individual patients [11].

In Malaysia, several local studies have shown that there was poor adherence to T2DM CPG recommendations among primary care providers (PCP) [12], [13], [14]. A huge gap between CPG recommendations and the actual practice was evident in the Audit Diabetes Control and Management study involving 70,889 adults with T2DM at primary care clinics, in which a majority of patients received suboptimal management and had poor glycemic control with mean $\mathrm{HbA} 1 \mathrm{c}$ of $8.3 \%$ [13]. A high-patient load, short consultation time, and cost constraint were among the barriers contributing to difficulties in translating CPG recommendations into clinical practice [15].

Health-care decision-makers have been seeking methods to improve the management of T2DM including adherence to CPG among PCP. The chronic care model (CCM) offers the solution to transform care for patients with chronic diseases including T2DM, to deliver high quality and patient-centered chronic disease care to the population [16], [17]. The application of CCM in managing T2DM in the Malaysian primary care setting can potentially maximize returns from limited resources by shifting from an acute to the chronic care approach [18]. The six elements of CCM include health-care organization, delivery system design, clinical information system, patient self-management support, decision support, and use of community resources [16], [17]. One of the CCM elements of interest is "decision support" which emphasizes the importance for providers to embed evidence-based guidelines into their daily clinical practice to improve outcomes for chronic conditions [16], [17].

The evidence on the effectiveness of one or more of CCM key elements in improving T2DM outcomes are well established in developed countries [19], [20]. A relatively modest clinicians' effort to incorporate elements of the CCM into their daily practices was associated with significantly improved processes and outcomes of diabetes care [21]. A study in Tuscany shows that diabetes care indicators improved after the implementation of CCM [22].

In developing countries, evidence on the effectiveness of CCM for T2DM is emerging. A study in the Philippines [23] and our EMPOWER-PAR study [24] showed that glycemic control improved after CCM implementation, supporting the restructuring of care in limited resource settings [23], [24]. In the EMPOWER-PAR study, we have pragmatically implemented three obligatory intervention components which were designed based on the CCM at selected public primary care clinics [24], [25]. One of the obligatory components included utilizing the T2DM CPG by the PCP (decision support) [25]. Evidence of CCM effectiveness in improving providers' adherence to clinical guidelines in developing countries is lacking. Therefore, the objective of this study was to evaluate the effectiveness of EMPOWER-PAR intervention in improving PCP's adherence to T2DM CPG in the Malaysian public primary care setting.

\section{Methods}

\section{Study design and participants}

This was a sub-study of the EMPOWER-PAR; a pragmatic, cluster-randomized, parallel, matched pair, and controlled trial using PAR approach [24] in ten public primary care clinics from two states in Malaysia. The study protocol was registered with the clinicaltrial. gov (NCT01545401) and was published in 2014 [25]. This paper reports the findings from the T2DM arm of the study and the reporting is done in accordance with the extension of CONSORT Statements on reporting pragmatic trials and cluster randomized trials [25].

\section{Site selection and recruitment}

All 34 public primary care clinics led by Family Medicine Specialists (FMS) in Selangor and Kuala Lumpur were invited to participate in this study. Eligibility of the clinics was assessed using the following criteria:

1. $\mathrm{Had} \geq 500$ patients with T2DM in the registry

2. Had an FMS who were keen to participate and willing to lead the team

3. Had the capacity and willing to implement the obligatory components of the EMPOWER-PAR intervention

4. Was located within $70 \mathrm{~km}$ from the central laboratory as the data and blood samples were transported back to the center for analysis.

Out of the 34 sites, only 20 fulfilled the eligibility criteria to enter the study. These 20 clinics were then matched according to their geographical locations (urban or sub-urban), workload and staffing into ten pairs. Clinics were matched according to these covariates as they were likely to affect the outcome variables, as the intervention was delivered at the cluster (clinics) level. Matching was employed before the randomization to ensure similarity between the intervention and control groups. The investigators then used computer generated tables to randomly select 
five out of the ten matched-pairs to be included into the study. Subsequently, one clinic in each pair was randomly allocated into the intervention or control arms.

\section{Patient recruitment}

Consecutive T2DM patients who attended the clinics within the 2-week recruitment period were invited to participate. They were given the patient information sheet and interviewed by the investigators in the waiting area. Screening was conducted to identify eligible participants based on the inclusion and exclusion criteria. Those who agreed and were eligible to participate were recruited. Written informed consents were obtained.

\section{Inclusion criteria}

Adults aged $\geq 18$ years who:

1. Were diagnosed with T2DM, or on treatment for T2DM

2. And received follow-up care for T2DM in the same clinic at least once in the past 1 year.

\section{Exclusion criteria}

Patients with the following criteria were excluded from the study:

1. Type 1 diabetes mellitus

2. Receiving renal dialysis

3. Presented with severe hypertension (HPT) (systolic blood pressure $[\mathrm{BP}]>180 \mathrm{mmHg}$ and/or diastolic BP>110 $\mathrm{mmHg}$ ) at recruitment

4. Diagnosed with conditions resulting in secondary HPT

5. Diagnosed with circulatory disorders requiring referral to secondary care over the past 1 year (e.g., unstable angina, heart attack, stroke, and transient ischemic attacks)

6. Receiving shared care at primary and secondary care centers for complications of T2DM

7. Pregnant

8. Enrolled in another study.

\section{The EMPOWER-PAR intervention}

The EMPOWER-PAR intervention was designed based on the six interrelated elements of the CCM. The details of its development have been described in the study protocol [25]. It consisted of three obligatory components and two optional components utilizing readily available and existing resources in the Malaysian public primary care setting [25]. The obligatory components included creating or strengthening the Chronic Disease Management (CDM) Team for diabetes care (delivery system design), utilizing the T2DM CPG by the CDM Team (decision support), and empowering patients with self-management skills through utilization of the Global Cardiovascular Risks Self-Management Booklet $^{\odot}$ (patient self-management support) [25].

\section{Delivery of the intervention}

The EMPOWER-PAR intervention was delivered for a period of 1-year. The intervention clinics received the EMPOWER-PAR intervention package, which consisted of CDM Workshops, T2DM CPG, self-management support tool, facilitation, and support.

The intervention was delivered in three phases:

\section{Phase 1: Formation and training of the CDM}

team

CDM team members were formed by each intervention clinic and were then trained in the CDM workshops. Details of the CDM workshops development, objectives and content were already published in the protocol paper [25]. In the workshop, the CDM team was trained to utilize the Malaysian CPG and the Quick References (QR) on the Management of T2DM [26] to support their clinical decision-making during consultations. They were also trained to empower their T2DM patients with knowledge and skills to selfmanage their condition using the Global CV Risks SelfManagement Booklet ${ }^{\odot}$ as a tool.

\section{Phase 2: Distribution and utilization of the intervention tools}

The Malaysian T2DM CPG, the QR, and the Global CV Risks Self-Management Booklet ${ }^{\odot}$ were distributed to all the intervention clinics. The CDM Teams were expected to utilize these tools in their dayto-day clinical practice.

\section{Phase 3: Facilitation and support to} implement the intervention

The intervention clinics received facilitation and support throughout the 1-year study period. Each clinic was assigned two facilitators to coach the CDM team, facilitate, and guide the implementation of intervention and provide feedback on their performance. Two site visits at 3 and 9 months were conducted over the 1-year intervention period. The facilitators monitored the utilization of T2DM CPG and the Global CV Risks Self-Management Booklet $^{\odot}$ in each clinic to ensure that it was delivered as intended throughout the 1-year period.

An intervention review workshop was also conducted 6 months after the commencement of intervention to allow interactions among the participating clinics and solve any arising problems. CPG training and feedback with regard to their baseline clinical outcomes were also delivered during this workshop [25]. 


\section{The control}

The control clinics continued with usual care with no additional intervention during the 1-year period. The control clinics have access to T2DM CPG as this is readily available on the internet. However, they did not receive CPG training and CPG utilization was not emphasized or monitored.

\section{Outcome measures}

Outcome measures were obtained from both intervention and control clinics at baseline and 1 year after the commencement of the intervention.

\section{Primary outcome}

Primary outcome was measured by the change in the proportion of patients achieving glycemic target of $\mathrm{HbA} 1 \mathrm{c}<6.5 \%(48 \mathrm{mmol} / \mathrm{mol})$.

\section{Secondary outcome}

Secondary outcome was the absolute change in the proportion of PCP's adherence to T2DM CPG as captured using the "Indicators of Care Pro forma" based on the recommendation by the Malaysian CPG on the Management of T2DM [26]

\section{Sample size}

The sample size was calculated based on the randomized clustered trial design using the PASS software (Copyright (c) 2009 by Dr Jerry L. Hintze, All Rights Reserved). A sample size of 626 (313 in each arm) was obtained by sampling ten clusters (five intervention vs. five control) with 63 subjects from each cluster to achieve $91 \%$ power to detect $25 \%$ difference in the proportion of subjects achieving target $\mathrm{HbA} 1 \mathrm{c}<6.5 \%$ (as the primary outcome of this study) from baseline and between the intervention and control groups. The test statistic used was the two-sided Z-test (unpooled). The significance level of the test was 0.05 . Therefore, after allowing for $25 \%$ dropout rate, this study aimed to recruit a total sample of 836 T2DM patients at baseline (i.e., 418 in each arm and 84 from each clinic).

\section{Data collection}

Socio-demographic data (age, gender, ethnic group, and education attainment) and data on PCP's adherence to T2DM CPG were obtained from the medical records using the "Indicators of Care Pro forma" (Appendix 1) from both the intervention and control clinics at baseline and at 1-year follow-up. The pro forma was developed by the investigators to capture the indicators of care for T2DM as recommended by the Malaysian CPG on the Management of T2DM [26]. It consists of four sections (history; physical examinations; investigations; and management) with 15 indicators. All investigators were trained regarding the study procedures before the conduct of the study to minimize variability in the method of data collection.

\section{Statistical analysis}

Age was described as mean \pm standard deviation (SD) in years, while categorical variables were described as frequencies and percentages. Independent t-test was used to compare the mean age between participants in the intervention and control groups. The Chi-square test was used for categorical variables to compare the proportion between the two groups. Mixed method model (random effect $=$ the cluster; fixed effect $=$ the intervention; and control groups) was used to analyze the difference in absolute change in the proportion of PCP' adherence to T2DM CPG at baseline and at 1-year follow-up.

\section{Results}

A total of 888 participants with T2DM were recruited at baseline (471 were in the intervention group, while 417 were in the control group). Figure 1 shows the EMPOWER-PAR CONSORT flow diagram. The result on the effectiveness of EMPOWER-PAR intervention in improving glycemic control (the primary outcome of this study) has already been published [24]. Therefore, this paper presents the result on the effectiveness of EMPOWER-PAR intervention in improving CPG adherence among PCP (secondary outcome).

Table 1 shows baseline socio-demographic characteristics of the participants. The two groups were comparable in terms of mean age, gender distribution, and education attainment. However, there was a significant difference in terms of ethnic distribution between the two groups in which there were more Malays in the intervention (51.4\%) versus control $(45.7 \%)$ and less Chinese in the intervention (15.1\%) versus control $(21.6 \%)$ groups.

Table 1: Demographic characteristics of participants with T2DM ( $\mathrm{n}=888)$

\begin{tabular}{|c|c|c|c|}
\hline Characteristics & Intervention $(n=471)$ & Control $(n=417)$ & $p$-value \\
\hline Age, years; mean ( \pm SD) & $57.3( \pm 10.2)$ & $57.9( \pm 10.5)$ & $0.363^{\psi}$ \\
\hline Gender; n (\%) & & & $0.444^{\gamma}$ \\
\hline Male & $180(38.2)$ & $149(35.7)$ & \\
\hline Female & $291(61.8)$ & $268(64.3)$ & \\
\hline Ethnicity; n (\%) & & & $0.010^{\gamma}$ \\
\hline Malay & $242(51.4)$ & $190(45.7)$ & \\
\hline Chinese & $71(15.1)$ & $90(21.6)$ & \\
\hline Indian & $157(33.3)$ & $130(31.3)$ & \\
\hline Other & $1(0.2)$ & $6(1.4)$ & \\
\hline Missing & 0 & $1(0)$ & \\
\hline Education attainment; $\mathrm{n}(\%)$ & & & $0.359^{\gamma}$ \\
\hline Primary & $187(41.1)$ & $157(39.4)$ & \\
\hline Secondary & $197(43.3)$ & $192(48.2)$ & \\
\hline Tertiary & $37(8.1)$ & $23(5.8)$ & \\
\hline None & $34(7.5)$ & $26(6.5)$ & \\
\hline Missing & $16(0)$ & $19(0)$ & \\
\hline
\end{tabular}




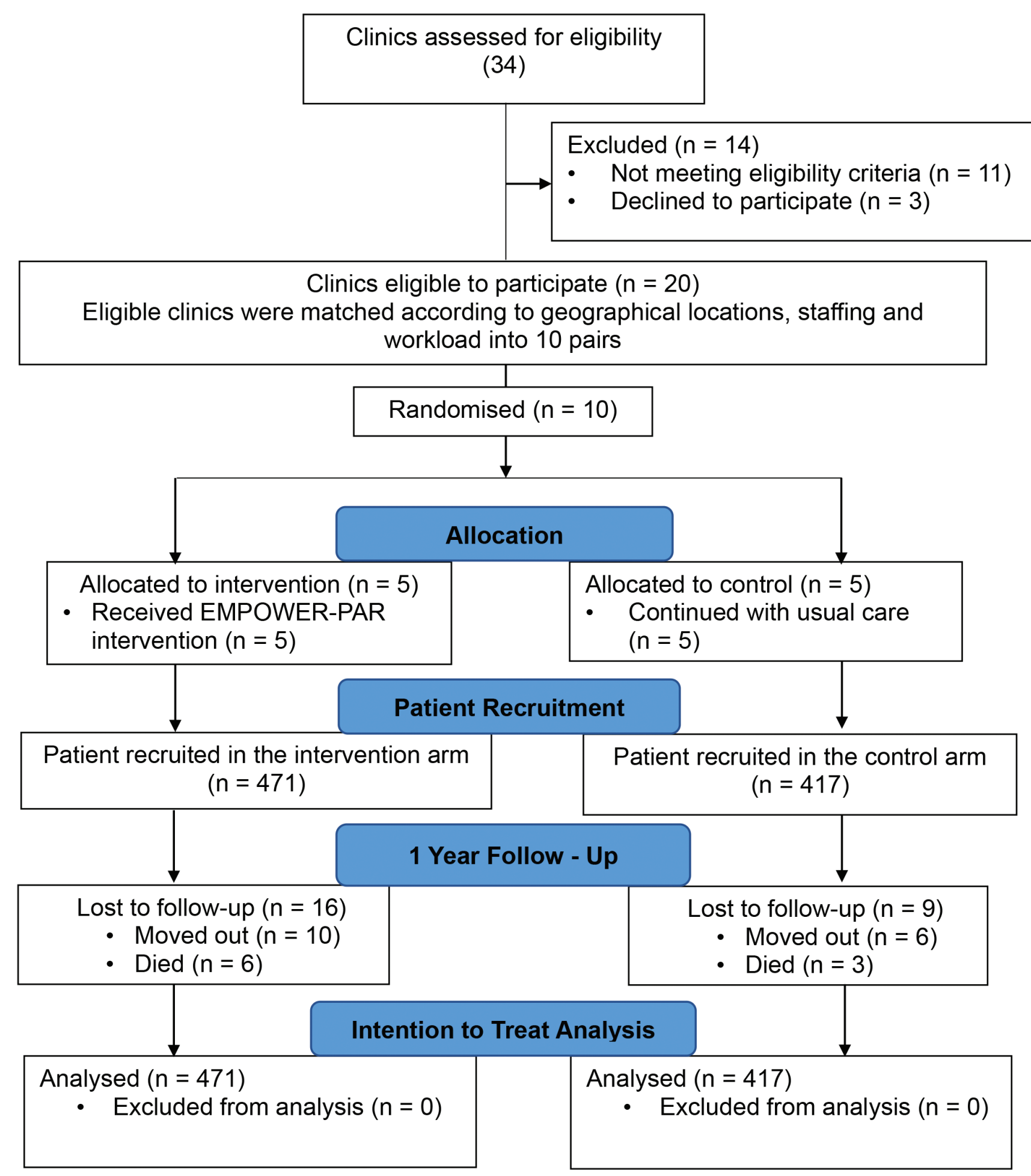

Figure 1: The EMPOWER-participatory action research consort flow diagram

Table 2 shows the comparison of absolute change in the indicators of care at 1-year follow-up between the intervention and control groups. There were significant improvements in the absolute change in the proportion of PCP' adherence for recording of BMI $(0.6 \%$ vs. $-1.8 \%, p<0.001)$; performing foot examination $(2.4 \%$ vs. $0.6 \%, p<0.001)$; performing funduscopy/fundus photography $(1.5 \%$ vs. $0.3 \%$, $p<0.001)$; monitoring renal profile $(0.9 \%$ vs. $-0.6 \%$, $p=0.001)$; measuring urine protein $(1.2 \%$ vs. $0.6 \%$, $p<0.001)$, and giving lifestyle modification and selfmanagement advice $(1.2 \%$ vs. $-0.3 \%, p<0.001)$ in the intervention group compared to the control group at 1-year follow-up. However, there was significant improvement in the absolute change in the proportion of PCP' adherence for performing ECG $(0.6 \%$ vs. $-0.9 \%, p=0.002$ ) in the control group compared to the intervention group at 1 -year follow-up. 
Table 2: Comparison of absolute change in the proportion of PCP's adherence to indicators of care at 1-year follow-up between control and intervention groups

\begin{tabular}{|c|c|c|c|c|c|c|c|}
\hline \multirow[t]{2}{*}{ Indicators of care } & \multicolumn{2}{|c|}{ Intervention } & \multirow{2}{*}{$\begin{array}{c}\text { Absolute } \\
\text { change }(\%)\end{array}$} & \multicolumn{2}{|c|}{ Control } & \multirow{2}{*}{$\begin{array}{c}\text { Absolute } \\
\text { change (\%) }\end{array}$} & \multirow[t]{2}{*}{ *p value } \\
\hline & Baseline (\%) & Follow-up (\%) & & Baseline (\%) & Follow-up (\%) & & \\
\hline \multicolumn{8}{|l|}{ History } \\
\hline $\begin{array}{l}\text { 1. Family history of premature CVD recorded once since } \\
\text { diagnosis }\end{array}$ & 100 & 100 & 0.00 & 100 & 100 & 0.00 & NA \\
\hline 2. Smoking status recorded at least once in the last 1 year & 6.6 & 5.4 & -1.2 & 5.4 & 4.5 & -0.9 & $<0.001$ \\
\hline $\begin{array}{l}\text { 3. The presence/absence of erectile dysfunction was screened } \\
\text { and recorded in adult males over the age of } 40 \text { years }\end{array}$ & 1.5 & 1.8 & 0.3 & 0.0 & 0.0 & - & $<0.001$ \\
\hline \multicolumn{8}{|l|}{ Physical Examinations } \\
\hline 4. BP was recorded at each visit & 100 & 100 & 0.00 & 100 & 100 & 0.00 & NA \\
\hline 5. BMI was recorded at least once in the last 1 year & 19.3 & 19.9 & 0.6 & 17.5 & 15.7 & -1.8 & $<0.001$ \\
\hline 6. WC was recorded at least once in the last 1 year & 15.7 & 16.3 & 0.6 & 15.4 & 14.8 & -0.6 & 0.855 \\
\hline 7. Foot examination was performed at least once in the last & 18.4 & 20.8 & 2.4 & 17.8 & 18.4 & 0.6 & $<0.001$ \\
\hline \multicolumn{8}{|l|}{$\begin{array}{l}1 \text { year } \\
\text { Investigation }\end{array}$} \\
\hline 8. FSL was measured at least once in the last 1 year & 22.0 & 21.7 & -0.3 & 19.3 & 17.8 & -1.5 & $<0.001$ \\
\hline 9. $\mathrm{HbA} 1 \mathrm{c}$ was measured every $6-12$ months & 60.8 & 61.7 & 0.9 & 60.8 & 60.5 & -0.3 & 0.152 \\
\hline $\begin{array}{l}\text { 10. Funduscopy/fundus photography was sperformed at least } \\
\text { once in the last } 1 \text { year }\end{array}$ & 19.3 & 20.8 & 1.5 & 17.8 & 18.1 & 0.3 & $<0.001$ \\
\hline 11. ECG was performed at least once in the last 1 year & 13.9 & 13.0 & -0.9 & 11.4 & 12.0 & 0.6 & 0.002 \\
\hline 12. RP was measured at least once in the last 1 year & 20.8 & 21.7 & 0.9 & 19.6 & 19.0 & -0.6 & 0.001 \\
\hline 13. Urine protein was measured at least once in the last 1 year & 65.4 & 66.6 & 1.2 & 66.6 & 67.2 & 0.6 & $<0.001$ \\
\hline \multicolumn{8}{|l|}{ Management } \\
\hline $\begin{array}{l}\text { 14. The interval between follow up visits did not exceed } 6 \\
\text { months within the last } 1 \text { year }\end{array}$ & 100 & 100 & 0.00 & 100 & 100 & 0.00 & NA \\
\hline $\begin{array}{l}\text { 15. Lifestyle modification and self-management advice was } \\
\text { given and recorded at least once in the last } 1 \text { year }\end{array}$ & 5.7 & 6.9 & 1.2 & 6.3 & 6.0 & -0.3 & $<0.001$ \\
\hline
\end{tabular}

of care at 1-year follow-up between control and intervention groups.

\section{Discussion}

The complexity of T2DM management remains a challenge to $\mathrm{PCP}$, despite the availability of established treatment standards and clinical guidelines [27]. The burgeoning burden of T2DM in Malaysia is taking its toll on the primary care workforce, resulting in sub-optimal management of the condition with evidence showing poor adherence to T2DM CPG among PCP [6], [13], [14]. The EMPOWERPAR was the first pragmatic randomized-controlled trial conducted in the Malaysian public primary care setting using resources which were readily available within the public primary care system with the aim to improve the adherence to T2DM CPG [25]. Its multifaceted interventions were conceptualized based on the CCM, which had been proven to be effective in improving providers' adherence to CPG in developed countries [28], [29], [30].

The EMPOWER-PAR was unique in its design as it utilized a pragmatic cluster randomized trial design, which is expected to measure the degree of beneficial effect of the intervention in real life clinical practice. In pragmatic trials, a balance between external validity (generalizability of the results) and internal validity (reliability or accuracy of the results) needs to be achieved [31]. In this study, the roles of PCP in the CDM team were strengthened, while reinforcing the adherence to T2DM CPG to support evidence based decision-making, and enhancing their skills to support patients' self-management. Flexibility on the implementation of the intervention was also allowed in line with the needs and constraints of the clinics.

We found that there were significant improvements in the absolute change in the proportion of PCPs' adherence to T2DM CPG in the intervention group with regard to the recording of BMI, performing foot examination, performing funduscopy/fundus photography, monitoring renal profile, measuring urine protein, and giving lifestyle modification and self-management advice. These findings were similar to a randomized controlled trial involving 504 patients (278 patients in the intervention practices and 226 patients in the control practices) which showed that the mean results of three annual performance measures (urine protein testing, funduscopy, and foot examination) had improved at 18-month follow-up in the intervention group as compared to the control group [32]. Another study of 208 patients showed that $85.5 \%$ had more than twice $\mathrm{HbA} 1 \mathrm{c}$ test done in a year, $93.6 \%$ had lipid profiles test, and $100 \%$ had foot examinations following a multifaceted intervention [33].

Our study has added to the body of evidence that multifaceted interventions targeted at physicians and organization is proven to enhance physicians' adherence to the recommended process of care. A systematic review of interventions to improve the adherence to cardiovascular disease guidelines described similar findings [34]. Another study in rural Kenya also found that providers' adherence to clinical guidelines increased significantly across all process measures with implementation of multifaceted intervention strategies [35]. A study in Turkey also observed improvements in the processes of T2DM care with multifaceted intervention, but no immediate improvement was seen in glycemic control or risk factors for chronic complications of T2DM [36]. All of these findings support the importance of multifaceted intervention, which include training $\mathrm{PCP}$ to utilize evidence-based guidelines (decision support) to improve indicators of care and clinical outcomes. 
This study also highlights the importance of PAR approach to promote adherence to CPG among PCP. Providers in this study were involved in designing the "Indicators of Care Pro forma" and giving their feedback on which indicators that were most important to improve the management of T2DM. The PAR approach empowered the PCP to contribute actively in the development of indicators of care, and also in making the plans of actions on how best to implement the intervention within their constraints.

The EMPOWER-PAR intervention which applied the CCM concept and the PAR approach has helped to improve the understanding on the complexity of the system and human factors which influenced adherence to CPG. Much of the previous research on CPG implementation has attempted to study the individual factors that were associated with success or failure of CPG utilization [37], [38]. The EMPOWER-PAR has broadened our understanding of CPG implementation at the patient and health-care unit levels.

\section{Study limitations}

Monitoring the intervention and ensuring its implementation posed a great challenge to the researchers in this study. It required multiple visits and encounters with PCP in the intervention clinics to ensure that the intervention was delivered as intended. Some of the intervention clinics faced constraints such as high staff turnover, high workload, and limited consultation time.

\section{research}

\section{Implications for clinical practice and future}

The EMPOWER-PAR has demonstrated that multifaceted intervention based on the CCM was effective in improving the PCP' adherence to T2DM CPG in several indicators of care in a resourceconstrained public primary care setting. Our previous publication has also shown that EMPOWER-PAR was effective in improving glycemic control [24]. This information would be pivotal in guiding the healthcare professionals and policy makers to make the necessary changes to the chronic disease delivery system, to ensure that patients are satisfied with the care that they receive.

However, given the constraints in the Malaysian public primary clinics such as high staff turnover, further research which includes a longer duration of intervention is needed to evaluate the sustainability of the intervention and its effectiveness. Future research may also include cost-effectiveness analysis of implementing the multifaceted intervention in the Malaysian primary care setting.

\section{Conclusions}

The EMPOWER-PAR intervention has been proven to be effective in improving the PCPs adherence to T2DM CPG in several indicators of care. Findings from this study provided objective evidence of the effectiveness of multifaceted intervention based on the CCM using PAR approach in the Malaysian public primary care setting.

\section{Ethics approval and consent to participate}

The Ethics Committee of UiTM and the Medical Research Ethics Committee of the Ministry of Health $(\mathrm{MOH})$, Malaysia approved the study protocol. Permission from the Family Health Development Division of the $\mathrm{MOH}$ and the respective Health District Offices was also obtained before the conduct of the study. Written informed consent was obtained from all participants before their study enrolment. Confidentiality of personal information was ensured at all times. Enrolment was done by the investigators and not the participants' attending doctors to reduce participants' perceived coercion to participate in the study.

\section{Availability of data and materials}

Technical appendix, statistical code, and dataset of this study is kept in secure database at the Institute of Pathology, Laboratory and Forensic Medicine (I-PPerForM), UiTM and at the Clinical Research Centre, $\mathrm{MOH}$ in Kuala Lumpur, Malaysia. Data can be shared on request and it is subjected to the data protection regulations.

\section{Author's Contribution}

ASR and $\mathrm{JH}$ conceptualized and designed the study. ASR and $\mathrm{JH}$ acquired the funding and coordinated the study. MHD, NKBMH, and SL made substantial contributions to the acquisition of data and monitoring the implementation of the intervention. MHD and TMITABS analyzed and interpreted the data. MHD, ASR, and SAR drafted the manuscript. All authors revised it critically for important intellectual content. All authors have read and given approval of the final manuscript. Each author has participated sufficiently in the work to take public responsibility for appropriate portions of the content as described above. All authors agreed to be accountable for all aspects of the work to ensure that questions related to the accuracy or integrity of any part of the work would be appropriately investigated and resolved. 


\section{Acknowledgments}

We would like to thank the Director General of Health Malaysia for his permission to publish this article. We are grateful to Dr Nazrila Hairizan Nasir, Dr Vickneswari Ayadurai, Dr Haslinda Hassan, Dr Salmiah Md. Sharif, Dr Naemah Sharifuddin $\mathrm{Dr}$ Rohaiyah Ismail, $\mathrm{Dr}$ Norhaslira Abd Rahim, Dr Rosnah Mat Isa, Dr Salmah Nordin, Dr Ho Bee Kiau and Dr Nik Suhaila Zakaria for their support and contribution in making the data collection and intervent.

\section{References}

1. Wild S, Roglic G, Green A, Sicree R, King H. Global prevalence of diabetes: Estimates for the year 2000 and projections for 2030. Diabetes Care. 2004;27(5):1047-53. https://doi. org/10.2337/diacare.27.5.1047

\section{PMid:15111519}

2. Guariguata L, Whiting DR, Hambleton I, Beagley J, Linnenkamp U, Shaw JE. Global estimates of diabetes prevalence for 2013 and projections for 2035. Diabetes Res Clin Pract. 2014;103(2):137-49. https://doi.org/10.1016/j. diabres.2013.11.002

PMid:24630390

3. Nanditha A, Ma RC, Ramachandran A, Snehalatha C, Chan JC, Chia KS, et al. Diabetes in asia and the pacific: Implications for the global epidemic. Diabetes Care. 2016;39(3):472-85. https:// doi.org/10.2337/dc15-1536

PMid:26908931

4. National Health and Morbidity Survey. Non-communicable Diseases, Risk Factors and other Health Problems. Vol. 2. National Health and Morbidity Survey; 2015. p. 1-315.

5. Feisul IM, Azmi S, Rizal AM, Zanariah H, Nik Mahir NJ, Fatanah I, et al. What are the direct medical costs of managing Type 2 diabetes mellitus in Malaysia? Med J Malaysia. 2017;72(5):271-7.

PMid:29197881

6. Mafauzy M, Hussein Z, Chan SP. The status of diabetes control in Malaysia: Results of diabcare 2008. Med J Malaysia. 2011;66(3):175-81.

\section{PMid:22111435}

7. International Diabetes Federation. IDF Diabetes Atlas. $7^{\text {th }}$ ed. Brussels: International Diabetes Federation; 2015. Available from: http://www.diabetesatlas.org. [Last accessed 2019 Feb 15].

8. Murray CJ, Vos T, Lozano R, Naghavi M, Flaxman $A D$, Michaud C, et al. Disability-adjusted life years (DALYs) for 291 diseases and injuries in 21 regions, 1990-2010: A systematic analysis for the global burden of disease study 2010. Lancet. 2012;380(9859):2197-223. https://doi.org/10.1016/ s0140-6736(12)61690-0 PMid:23245608

9. Seidu S, Khunti K. Non-adherence to diabetes guidelines in primary care - the enemy of evidence-based practice. Diabetes Res Clin Pract. 2012;95(3):301-2. https://doi.org/10.1016/j. diabres.2012.01.015

PMid:22293930

10. Oh SW, Lee HJ, Chin HJ, Hwang Jl. Adherence to clinical practice guidelines and outcomes in diabetic patients. Int J Qual Health Care. 2011;23(4):413-9.

PMid:21705772

11. Barth $\mathrm{JH}$, Misra S, Aakre $\mathrm{KM}$, Langlois MR, Watine J, Twomey PJ, et al. Why are clinical practice guidelines not followed? Clin Chem Lab Med. 2016;54(7):1133-9. https://doi. org/10.1515/cclm-2015-0871

PMid:26650076

12. Chew BH, Shariff-Ghazali S, Lee PY, Cheong AT, Mastura I, Haniff J, et al. Type 2 diabetes mellitus patient profiles, diseases control and complications at four public health facilities a cross-sectional study based on the adult diabetes control and management (ADCM) registry 2009. Med J Malaysia. 2013;68(5):397-404. https://doi.org/10.1186/1475-2840-11-54 PMid:24632869

13. Mastura I, Chew BH, Lee PY, Cheong AT, Sazlina SG, Jamaiyah $\mathrm{H}$, et al. Control and treatment profiles of 70,889 adult Type 2 diabetes mellitus patients in Malaysia a cross sectional survey in 2009. Int J Collab Res Intern Med Public Health. 2011;3(1):97-113.

14. Sazlina SG, Zailinawati AH, Zaiton A, Ong I. A clinical audit on diabetes care in two urban public primary care clinics in Malaysia. Malays J Med Health Sci. 2010;6(1):101-9.

15. Ramli AS, Taher SW. Managing chronic diseases in the Malaysian primary health care a need for change. Malays Fam Phys. 2008;3(1):7-13.

16. Bodenheimer T, Wagner EH, Grumbach K. Improving primary care for patients with chronicillness. JAMA. 2002;288(14):1775-9. https://doi.org/10.1001/jama.288.14.1775

PMid:12365965

17. Rothman AA, Wagner EH. Chronic illness management: What is the role of primary care? Ann Intern Med. 2003;138(3):256-61. https://doi.org/10.7326/0003-4819-138-3-200302040-00034 PMid: 12558376

18. Hussein Z, Taher SW, Singh HK, Swee WC. Diabetes care in Malaysia: Problems, new models, and solutions. Ann Glob Health. 2015;81(6):851-62. https://doi.org/10.1016/j. aogh.2015.12.016

PMid:27108152

19. Bongaerts BW, Mussig K, Wens J, Lang C, Schwarz P, Roden M, et al. Effectiveness of chronic care models for the management of Type 2 diabetes mellitus in Europe: A systematic review and meta-analysis. BMJ Open. 2017;7(3):e013076. https://doi. org/10.1136/bmjopen-2016-013076

PMid:28320788

20. Stellefson M, Dipnarine K, Stopka C. The chronic care model and diabetes management in US primary care settings: A systematic review. Prev Chronic Dis. 2013;10:26. https://doi. org/10.5888/pcd 10.120180 PMid:23428085

21. Nutting PA, Dickinson WP, Dickinson LM, Nelson CC, King DK, Crabtree BF, et al. Use of chronic care model elements is associated with higher-quality care for diabetes. Ann Fam Med. 2007;5(1):14-20. https://doi.org/10.1370/afm.610 PMid: 17261860

22. Barletta V, Profili F, Gini R, Grilli L, Rampichini C, Matarrese D, et al. Impact of chronic care model on diabetes care in tuscany: A controlled before-after study. Eur J Public Health. 2017;27(1):813. https://doi.org/10.1093/eurpub/ckw189 PMid:28177456

23. Ku GM, Kegels G. Implementing elements of a context-adapted chronic care model to improve first-line diabetes care: Effects on assessment of chronic illness care and glycaemic control among people with diabetes enrolled to the first-line diabetes care (FiLDCare) project in the Northern Philippines. Prim Health Care Res Dev. 2015;16(5):481-91. https://doi.org/10.1017/ 


\section{s1463423614000553}

PMid:25600305

24. Ramli AS, Selvarajah S, Daud MH, Haniff J, Abdul-Razak S, Tg-Abu-Bakar-Sidik TM, et al. Effectiveness of the EMPOWERPAR intervention in improving clinical outcomes of Type 2 diabetes mellitus in primary care: A pragmatic cluster randomised controlled trial. BMC Fam Pract. 2016;17(1):157. https://doi.org/10.1186/s12875-016-0557-1 PMid:27842495

25. Ramli AS, Lakshmanan S, Haniff J, Selvarajah S, Tong SF, Bujang MA, et al. Study protocol of EMPOWER Participatory Action Research (EMPOWER-PAR): A pragmatic cluster randomised controlled trial of multifaceted chronic disease management strategies to improve diabetes and hypertension outcomes in primary care. BMC Fam Pract. 2014;15(1):151. https://doi.org/10.1186/1471-2296-15-151 PMid:25218689

26. Ministry of Health. Clinical Practice Guideline on Management of Type 2 Diabetes Mellitus. $5^{\text {th }}$ ed. Malaysia: Ministry of Health; 2015. Available from: http://www.moh.gov.my/moh/ resources/Penerbitan/CPG/Endocrine/3a.pdf. [Last accessed on 2019 Feb 18].

27. Rushforth B, McCrorie C, Glidewell L, Midgley E, Foy R. Barriers to effective management of Type 2 diabetes in primary care: Qualitative systematic review. Br J Gen Pract. 2016;66(643):11427. https://doi.org/10.3399/bjgp16x683509 PMid:26823263

28. van Bruggen R, Gorter KJ, Stolk RP, Verhoeven RP, Rutten GE. Implementation of locally adapted guidelines on Type 2 diabetes. Fam Pract. 2008;25(1):430-7. https://doi.org/10.1093/ fampra/cmn045

PMid:18718886

29. Bertoni AG, Bonds DE, Chen H, Hogan P, Crago L, Rosenberger $\mathrm{E}$, et al. Impact of a multifaceted intervention on cholesterol management in primary care practices. Arch Intern Med. 2009;169(7):678-86. https://doi.org/10.1001/ archinternmed.2009.44 PMid:19364997

30. Putnam LR, Levy SM, Sajid M, Dubuisson DA, Rogers NB, Kao LS, et al. Multifaceted interventions improve adherence to the surgical checklist. Surgery. 2014;156(2):336-44. https://doi. org/10.1016/j.surg.2014.03.032 PMid:24947646

31. Godwin M, Ruhland L, Casson I, MacDonald S, Delva D, Birtwhistle $\mathrm{R}$, et al. Pragmatic controlled clinical trials in primary care: The struggle between external and internal validity. BMC Med Res Methodol. 2003;3(1):28. https://doi. org/10.1186/1471-2288-3-28

PMid:14690550

32. Samoutis GA, Soteriades ES, Stoffers HE, Philalithis A, Delicha EM, Lionis C. A pilot quality improvement intervention in patients with diabetes and hypertension in primary care settings of Cyprus. Fam Pract. 2010;27(3):263-70. https://doi. org/10.1093/fampra/cmq009

PMid:20348163

33. Zgibor JC, Rao H, Wesche-Thobaben J, Gallagher N McWillinms J, Korytkozuski MT. Improving the quality of diabetes care in primary care practice. J Healthc Qual. 2004;26(4):14-21. https://doi.org/10.1111/j.1945-1474.2004.tb00502.x PMid: 15352340

34. Jeffery RA, To MJ, Hayduk-Costa G, Cameron A, Taylor C, Van Zoost $C$, et al. Interventions to improve adherence to cardiovascular disease guidelines: A systematic review. BMC Fam Pract. 2015;16(1):147. https://doi.org/10.1186/ s12875-015-0341-7 PMid:26494597

35. English M, Nzinga J, Mbindyo P, Ayieko P, Irimu G, Mbaabu L. Explaining the effects of a multifaceted intervention to improve inpatient care in rural Kenyan hospitals--interpretation based on retrospective examination of data from participant observation, quantitative and qualitative studies. Implement Sci. 2011;6(1):124. https://doi.org/10.1186/1748-5908-6-124 PMid:22132875

36. Satman I, Imamoglu S, Yilmaz C, Admire Study Group. A patientbased study on the adherence of physicians to guidelines for the management 0

f Type 2 diabetes in Turkey. Diabetes Res Clin Pract. 2012;98(1):7582. https://doi.org/10.1016/j.diabres.2012.05.003 PMid:22652276

37. Farquhar CM, Kofa EW, Slutsky JR. Clinicians' attitudes to clinical practice guidelines: A systematic review. Med J Aust. 2002;177(9):502-6. https://doi.org/10.5694/j.1326-5377.2002. tb04920.x PMid:12405894

38. Lesho EP, Myers CP, Ott M, Winslow C, Brown JE. Do clinical practice guidelines improve processes or outcomes in primary care? Mil Med. 2005;170(3):234-46. https://doi.org/10.7205/ milmed.170.3.243

PMid:15828703 


\section{Appendix}

Appendix 1. The Indicators of care proforma

\begin{tabular}{|c|c|}
\hline Section & Indicators of Care \\
\hline History & $\begin{array}{l}\text { 1. Family history of premature CVD was recorded once since diagnosis } \\
\text { (yes/no) } \\
\text { 2. Smoking status was recorded at least once in the last } 1 \text { year (yes/no) } \\
\text { 3. Presence or absence of erectile dysfunction was screened and } \\
\text { recorded in adult males over the age of } 40 \text { years (yes } / \text { no) }\end{array}$ \\
\hline $\begin{array}{l}\text { Physical } \\
\text { examinations }\end{array}$ & $\begin{array}{l}\text { 4. Blood pressure (BP) was recorded at each visit (yes/no) } \\
\text { 5. Body mass index (BMI) was recorded at least once in the last } 1 \text { year } \\
\text { (yes/no) } \\
\text { 6. Waist circumference }(\mathrm{WC}) \text { was recorded at least once in the last } 1 \\
\text { year (yes/no) } \\
\text { 7. Foot examination was performed at least once in the last } 1 \text { year (yes/no) }\end{array}$ \\
\hline Investigations & $\begin{array}{l}\text { 8. Fasting Serum Lipid (FSL) was measured at least once in the last } 1 \\
\text { year (yes/no) } \\
\text { 9. HbA1c was measured every } 6-12 \text { months (yes/no) } \\
\text { 10. Funduscopy/fundus photography was performed at least once in the } \\
\text { last } 1 \text { year (yes/no) } \\
\text { 11. ECG was performed at least once in the last } 1 \text { year (yes/no) } \\
\text { 12. Renal Profile (RP) was measured at least once in the last } 1 \text { year } \\
\text { (yes/no) }\end{array}$ \\
\hline
\end{tabular}

